\title{
Synthesis of guanidinoacetate and creatine from amino acids by rat pancreas
}

\author{
Robin P. da Silvat, Kathy Clow, John T. Brosnan and Margaret E. Brosnan* \\ Department of Biochemistry, Memorial University of Newfoundland, St John's, NL, Canada A1B 3X9
}

(Submitted 14 May 2013 - Final revision received 24 July 2013 - Accepted 14 August 2013 - First published online 8 October 2013)

\section{Abstract}

Creatine is an important molecule involved in cellular energy metabolism. Creatine is spontaneously converted to creatinine at a rate of $1.7 \%$ per $\mathrm{d}$; creatinine is lost in the urine. Creatine can be obtained from the diet or synthesised from endogenous amino acids via the enzymes arginine:glycine amidinotransferase (AGAT) and guanidinoacetate $N$-methyltransferase (GAMT). The liver has high GAMT activity and the kidney has high AGAT activity. Although the pancreas has both AGAT and GAMT activities, its possible role in creatine synthesis has not been characterised. In the present study, we examined the enzymes involved in creatine synthesis in the pancreas as well as the synthesis of guanidinoacetate (GAA) and creatine by isolated pancreatic acini. We found significant AGAT activity and somewhat lower GAMT activity in the pancreas and that pancreatic acini had measurable activities of both AGAT and GAMT and the capacity to synthesise GAA and creatine from amino acids. Creatine supplementation led to a decrease in AGAT activity in the pancreas, though it did not affect its mRNA or protein abundance. This was in contrast with the reduction of AGAT activity and mRNA and protein abundance in the kidney, suggesting that the regulatory mechanisms that control the expression of this enzyme in the pancreas are different from those in the kidney. Dietary creatine increased the concentrations of GAA, creatine and phosphocreatine in the pancreas. Unexpectedly, creatine supplementation decreased the concentrations of $S$-adenosylmethionine, while those of $S$-adenosylhomocysteine were not altered significantly.

\section{Key words: Phosphocreatine: Pancreatic acini: S-Adenosylmethionine: Arginine: Glycine: Methionine}

Creatine is a key molecule for the maintenance of cellular ATP levels in cells such as those in the muscle and brain, which have high activities of creatine kinase. Creatine and phosphocreatine together with the enzyme creatine kinase act as buffers for ATP in cells. In addition, phosphocreatine is a carrier of 'high-energy' phosphate between sites of ATP synthesis and utilisation ${ }^{(1)}$. Creatine and phosphocreatine are spontaneously converted to creatinine at a rate of about $1.7 \%$ per $\mathrm{d}$, and this is lost in the urine ${ }^{(2)}$. Therefore, this quantity of creatine must be replaced for the maintenance of constant levels of creatine in the body. Creatine can be obtained from the diet by ingestion of meat and dairy products and through endogenous synthesis from amino acids.

Creatine is synthesised de novo from the metabolism of the amino acids arginine, glycine and methionine. The enzymes involved in its synthesis are arginine:glycine amidinotransferase (AGAT) and guanidinoacetate $N$-methyltransferase (GAMT). AGAT catalyses the transfer of the amidino group of arginine onto the $\mathrm{N}$ of glycine, giving ornithine and guanidinoacetate (GAA). GAMT is then responsible for the transfer of a methyl group from $S$-adenosylmethionine (SAM) onto the
$\mathrm{N}_{\mathrm{E}}$ nitrogen of GAA, which gives creatine ${ }^{(3)}$. In vertebrates, the highest activities of GAMT can be found in the liver, pancreas and brain, while the highest activities of AGAT have been measured in the kidney, pancreas and brain ${ }^{(4)}$.

We have recently shown that the rat kidney can produce GAA in sufficient quantities to replace creatinine lost in the urine $^{(5)}$. In addition, we have shown that the liver has a maximum capacity to methylate GAA that is far greater than that required to replace the daily loss of creatine ${ }^{(6)}$. However, the actual hepatic methylation of GAA is limited by the delivery of GAA. What is then the function of the creatine synthetic enzymes in other tissues, such as the brain and pancreas? Creatine synthesis in the brain has been thoroughly examined by Braissant $\&$ Henry $^{(7)}$, who suggested that the adult rat brain may be able to produce enough creatine to satisfy its own requirements. Although the pancreas has been reported to have the activities of the enzymes responsible for creatine synthesis $^{(4)}$, any possible role of this organ in creatine synthesis is not yet clear.

Sorenson et al. ${ }^{(8)}$ have shown that AGAT is present only in the mitochondria of pancreatic acini. When the pancreas is

\footnotetext{
Abbreviations: AGAT, arginine:glycine amidinotransferase; GAA, guanidinoacetate; GAMT, guanidinoacetate $N$-methyltransferase; SAH, $S$-adenosylhomocysteine; SAM, S-adenosylmethionine.
}

*Corresponding author: M. E. Brosnan, fax +1709 8642422, email mbrosnan@mun.ca

† Present address: Department of Agricultural, Food and Nutritional Science, University of Alberta, Edmonton AB, Canada T6G 2 E1. 
perfused with arginine and glycine, ornithine is released into the perfusate. These investigators concluded that ornithine and GAA, the second product of AGAT, could be transported to the liver by the portal vein. They did not look for GAMT in the pancreas, although Van Pilsum et al. ${ }^{(4)}$ did find some evidence for low activity in the pancreas of a number of species.

In the present study, we determined whether the pancreas is capable of synthesising creatine from amino acids. Sorenson et $a l .{ }^{(8)}$ reported that the catalytic activity and immunoreactivity of AGAT can be found in the acinar cells, which make up approximately $80 \%$ of the cells in the pancreas ${ }^{(9)}$. Thus, we studied both the intact pancreas and isolated pancreatic acini. Since there is a known down-regulation of AGAT activity in the kidney on supplementation of a diet with creatine ${ }^{(10)}$, we also examined whether creatine could regulate the activity of enzymes involved in creatine synthesis in the pancreas.

\section{Experimental methods}

\section{Animals}

Male Sprague-Dawley rats, body weight between 250 and $350 \mathrm{~g}$, were used for the experiments. All the rats were fed ad libitum and kept under a $12 \mathrm{~h}$ light $-12 \mathrm{~h}$ dark cycle in a climate-controlled room. The control rats were fed the American Institute of Nutrition diet 93 for growth and lactation. For the creatine supplementation study, the experimental group was fed an American Institute of Nutrition diet 93 for growth and lactation containing $0.4 \%$ creatine, by weight, instead of an equivalent amount of maize starch. Both the dietary treatment groups were fed for a period of $14 \mathrm{~d}$. All the procedures were approved by the Memorial University of Newfoundland Institutional Animal Care Committee and were in accordance with the Guidelines of the Canadian Council of Animal Care.

\section{Tissue collection}

The rats were anaesthetised with sodium pentobarbital, intraperitoneal, at a dose of $65 \mathrm{mg} / \mathrm{kg}$ body weight. The pancreases of the rats were removed for the isolation of acini and measurement of GAMT activity as described in detail below. The kidneys and a portion of the pancreases were freezeclamped in $\mathrm{Al}$ tongs pre-cooled in liquid $\mathrm{N}_{2}$ and stored at $-80^{\circ} \mathrm{C}$ for the analysis of metabolites, mRNA and AGAT activity.

\section{Isolation of pancreatic acini}

Pancreatic acini were isolated according to a modification of a previously published method ${ }^{(11)}$. Immediately after removal from the rats, the pancreases were placed in a Petri dish where any visible adipose tissue was dissected and separated from the pancreatic tissue. The pancreases were injected with $5 \mathrm{ml}$ of Solution A (Krebs-Henseleit solution containing $1.3 \mathrm{~mm}$-calcium chloride, $10 \mathrm{~mm}$-glucose, $2.1 \mathrm{~mm}$-lactate, $0 \cdot 15 \mathrm{~mm}$-pyruvate, $0 \cdot 2 \% \mathrm{w} / \mathrm{v}$ fatty acid-free bovine serum albumin, and $135 \mathrm{U} / \mathrm{ml}$ collagenase (type 4)) and placed in a $50 \mathrm{ml}$ Erlenmeyer flask, together with $25 \mathrm{ml}$ of Solution A. The air in the flask was replaced with $95 \% \mathrm{O}_{2} / 5 \% \mathrm{CO}_{2}$ by gassing for $30 \mathrm{~s}$, and the flask was stoppered and placed in a shaking water-bath at $37^{\circ} \mathrm{C}$ for $15 \mathrm{~min}$. A continuous stream of $95 \% \mathrm{O}_{2} / 5 \% \mathrm{CO}_{2}$ gas was fed through the stopper throughout the isolation procedure. After $15 \mathrm{~min}$, the collagenase solution was removed, fresh Solution A (with collagenase) was added and the flask was shaken for another $15 \mathrm{~min}$. This wash was repeated once more. Solution A was then removed and $10 \mathrm{ml}$ of Solution B was added to the flask. Solution $\mathrm{B}$ had the same composition as Solution A, but with $4 \%$ bovine serum albumin and without collagenase. The pancreases were gently teased apart by repetitive pipetting through plastic pipettes with decreasing bore sizes. The suspension was passed through a $250 \mu \mathrm{m}$ filter and centrifuged at $200 \mathrm{~g}$ for $2 \mathrm{~min}$. The supernatant was removed and the acini were re-suspended in fresh Solution B. This wash was repeated three times. Finally, the acini were re-suspended in Krebs-Henseleit medium containing $0.2 \%$ bovine serum albumin. Viability was assessed by means of trypan blue exclusion.

Incubations were initiated by the addition of aliquots of the pancreatic acini suspension into pre-warmed $\left(37^{\circ} \mathrm{C}\right) 25 \mathrm{ml}$ Erlenmeyer flasks containing Krebs-Henseleit medium and substrates. Acini were incubated at near-physiological concentrations of amino acid substrates $(0 \cdot 2 \mathrm{~mm}$-arginine and $0.2 \mathrm{~mm}$-glycine $)$ or at high concentrations $(2.0 \mathrm{~mm}$-arginine and $2.0 \mathrm{~mm}$-glycine). Methionine $(0.5 \mathrm{~mm})$ was used for all the incubations. The air inside each Erlenmeyer flask was replaced with $95 \% \mathrm{O}_{2} / 5 \% \mathrm{CO}_{2}$ by gassing for $20 \mathrm{~s}$ and sealing with a rubber stopper. Incubations were carried out at $37^{\circ} \mathrm{C}$ for $40 \mathrm{~min}$ in triplicate. Incubations were stopped by the addition of $100 \mu \mathrm{l}$ of ice-cold $30 \%(\mathrm{w} / \mathrm{v})$ perchloric acid. Precipitated protein was pelleted at $10000 \mathrm{~g}$ for $10 \mathrm{~min}$ at room temperature. Later, $700 \mu \mathrm{l}$ of the supernatants were removed and neutralised with $20 \mu \mathrm{l}$ of universal indicator, $40 \mu \mathrm{l}$ of $50 \%$ $(\mathrm{w} / \mathrm{v}) \mathrm{K}_{2} \mathrm{CO}_{3}$ and $20 \%(\mathrm{w} / \mathrm{v}) \mathrm{KOH}$ until the $\mathrm{pH}$ was between 6 and 8. After allowing the supernatants to stand in ice for $15 \mathrm{~min}$, precipitated salts were removed by centrifugation at $10000 \mathrm{~g}$ for $5 \mathrm{~min}$ at room temperature. The supernatants were then assayed for creatine as described below. Aliquots of cells that were not subjected to de-proteinisation were assayed for GAMT and AGAT activities as described below.

\section{Enzyme activities}

GAMT activity was assayed using fresh tissue according to a previously described method ${ }^{(6)}$. AGAT activity was assayed using fresh or frozen tissue as described previously ${ }^{(12)}$. Total protein in all the tissue homogenates was assayed using the Biuret method.

\section{Real-time PCR}

Frozen pancreatic tissue $\left(-80^{\circ} \mathrm{C}\right)$ was ground into a fine powder in a ceramic mortar and pestle pre-cooled with liquid $\mathrm{N}_{2}$. Approximately $100 \mathrm{mg}$ of powdered tissue were 
placed in a sterilised microcentrifuge tube containing $500 \mu \mathrm{l}$ of ice-cold TRIzol reagent and homogenised immediately. Total RNA was extracted using the standard TRIzol extraction protocol provided by Invitrogen. RNA quality was assessed by separation on an agarose gel and also by measuring absorbance at 260 and $280 \mathrm{~nm}$ using a NanoDrop spectrophotometer system (Thermo Fisher Limited). Primers were designed using the Primer3Plus online software and obtained from Integrated DNA Technologies. PCR was carried out with a Roche LightCycler using LightCycler3 software (Roche Applied Science). The AGAT forward primer was 'CTGTGCAGCTGAAGACAAGG' and the reverse primer was 'CTGTGAATGGTGGGACACAG'. The GAMT forward primer was 'ACTCATGCTTTCCGTTTGCT' and the reverse primer was 'AGGCACCTGAGTCTCCTCAA'. Target RNA were normalised to $18 \mathrm{~S}$ ribosomal RNA with the forward primer 'GTGATCCCCGAGAAGTTTCA' and the reverse primer 'CTGCTTTCCTCAACACCACA'.

Guanidinoacetate, creatine, phosphocreatine, ATP,

S-adenosylmethionine and S-adenosylhomocysteine measurement

GAA and creatine were assayed by the HPLC method of Buchberger \& Ferdig ${ }^{(13)}$. HPLC was carried out using a Waters 600E solvent delivery system and a Waters 717 autosampler (Waters Corporation). Phosphocreatine and ATP were assayed by the enzymatic method of Lowry \& Passonneau ${ }^{(14)}$. SAM and SAH were assayed as described previously ${ }^{(15)}$.

\section{Western blotting}

AGAT protein was detected using an affinity-purified antiAGAT rabbit polyclonal antibody raised against the sequence RPDPIDWSLKYKTPDFE, amino acids $142-159$ of rat AGAT (accession no. P50442-1) (Open Biosystems). The secondary antibody was a horseradish peroxidase-conjugated anti-rabbit IgG (Bio-Rad), visualised using the Immun-Star Chemiluminescence System (Bio-Rad). Band detection was carried out using an enhanced luminol system (Immun-Star, Bio-Rad, Inc.) and analysed with an Alpha Innotech ChemiImager 4400 (Alpha Innotech). Results were normalised to $\beta$-actin.

\section{Reagents}

All the reagents were purchased from Sigma Aldrich with the exception of collagenase, obtained from Worthington, and perchloric acid, obtained from Fisher Scientific. All the reagents used for PCR were purchased from Invitrogen.

\section{Statistical analyses}

Statistical analyses were carried out using the Prism GraphPad software version 3.02 (Prism Software Corporation). Data were compared using unpaired Student's $t$ tests with the exception of the data obtained during the incubations of the isolated pancreatic acini, which were analysed using paired Student's $t$ tests. A $P$ value $<0.05$ was considered to be significant.

\section{Results}

\section{Regulation of creatine synthetic enzymes by} dietary creatine

We examined the pancreatic activities and mRNA and protein abundance of key enzymes required for creatine synthesis in the pancreas of rats fed the creatine-free or creatinesupplemented diets. The average weights of the pancreas were 1.38 (SE 0.21) and 1.47 (SE 0.12) g ( $n 5$ each) for the control and creatine-supplemented diet-fed groups, respectively. There was no significant difference between the dietary treatment groups with regard to the weight of the pancreas.

The enzyme activity and relative mRNA expression of AGAT and GAMT in the pancreas are shown in Fig. 1 along with the protein abundance of AGAT. Creatine supplementation reduced pancreatic AGAT activity by $34 \%$, while its protein and mRNA levels remained unchanged. Pancreatic GAMT activity and mRNA levels were not affected by dietary creatine. We were unable to measure GAMT protein levels by Western blotting due to the lack of a suitable antibody. For comparison, renal AGAT activity and protein and mRNA abundance are shown in Fig. 2. A much greater effect of dietary creatine on renal AGAT activity was observed, which was reduced by $83 \%$ in rats fed the creatine-supplemented diet. The relative expression of AGAT mRNA and protein in the kidneys of the creatine-supplemented diet-fed rats was also reduced by 47 and $60 \%$, respectively.

\section{Effect of dietary creatine supplementation on metabolites in the pancreas}

We examined the pancreatic content of several metabolites in rats fed the creatine-free or creatine-supplemented diets. The concentrations of these are given in Table 1 . The pancreatic content of GAA, creatine and phosphocreatine was 5-fold, 3 -fold and 2-fold higher, respectively, in the creatinesupplemented diet-fed rats than in the control rats. The concentration of SAM in the pancreas of the creatinesupplemented diet-fed rats was only $65 \%$ of that observed in the control rats. The concentration of SAH as well as the SAM:SAH ratio in the pancreas was not statistically different between the dietary treatment groups.

\section{Creatine synthesis in pancreatic acini}

The activities of AGAT and GAMT in pancreatic acini are summarised in Table 2 . It can be seen that GAMT activity was only $2.3 \%$ of AGAT activity. The rates of GAA production in the isolated pancreatic acini are shown in Fig. 3. Pancreatic acini produced significant quantities of GAA in the presence of physiological concentrations of methionine $(0.5 \mathrm{~mm})$, glycine $(0.2 \mathrm{~mm})$ and arginine ( $0.2 \mathrm{~mm})$. In the presence of high concentrations of arginine and glycine ( $2 \mathrm{~mm}$ of each), GAA production in the pancreatic acini was approximately 8-fold higher than that observed in the presence of near-physiological concentrations of these amino acids. The pancreatic acini were capable of synthesising about the same amount of creatine and GAA at physiological substrate concentrations, although the 
(a)

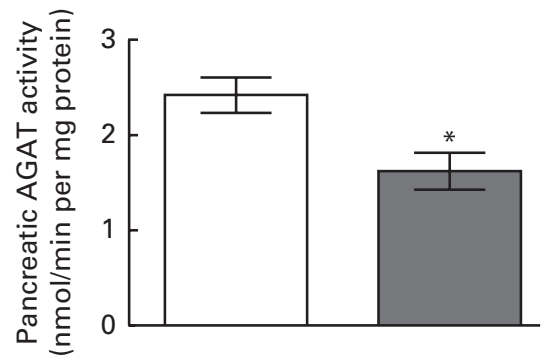

(b)

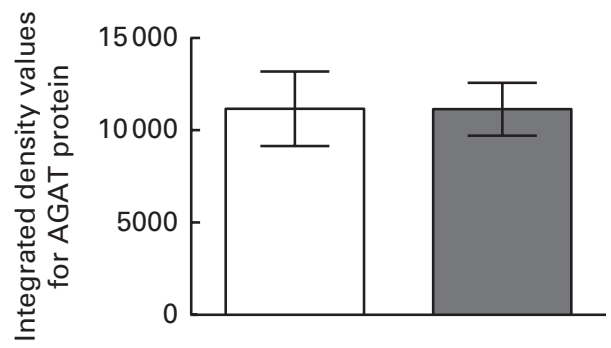

(c)

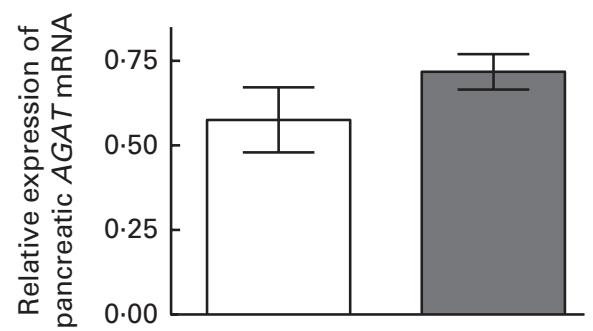

(d)

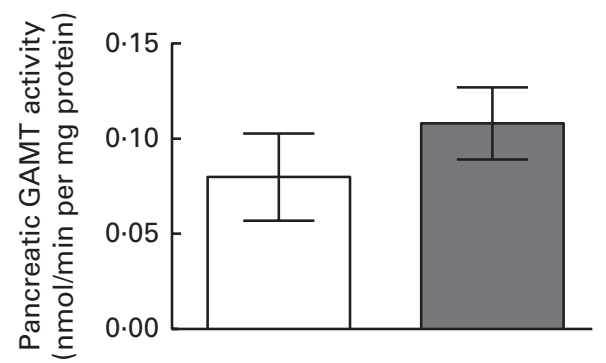

(e)

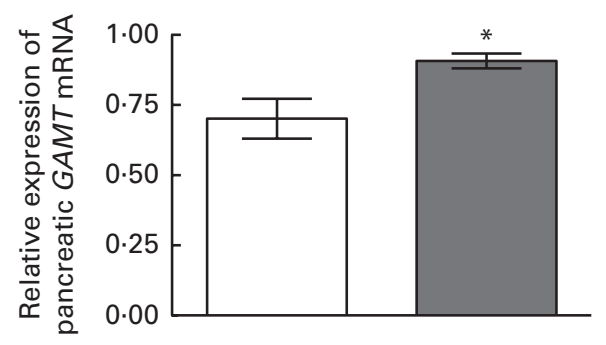

Fig. 1. Effect of dietary creatine on pancreatic arginine:glycine amidinotransferase (AGAT) and guanidinoacetate $N$-methyltransferase (GAMT). (a) AGAT enzyme activity, (b) integrated density values from AGAT Western blotting, (c) relative expression of AGAT mRNA in the pancreas, (d) GAMT enzyme activity and (e) relative expression of GAMT mRNA in the pancreas. Creatine-free diet-fed group $(\square)$ and creatine-supplemented diet-fed group ( $\square$ ). Data for mRNA target genes were normalised to 18S ribosomal RNA. Values are means $(n 5)$, with their standard errors represented by vertical bars. * Mean values were significantly different between the dietary treatment groups $(P<0.05)$. rates of creatine synthesis were much lower than those of GAA synthesis at higher substrate concentrations. The capacity for creatine and GAA production in pancreatic acini, therefore, is evenly matched at physiological concentrations, but the capacity for GAA production is greater than that for GAA methylation (creatine production) at elevated substrate concentrations.

\section{Discussion}

Significant AGAT activity and GAA production were observed in the pancreatic acini. This was in agreement with the immunohistochemical localisation of AGAT protein exclusively in the pancreatic $\operatorname{acini}^{(8)}$ and the determination of AGAT activity $^{(4)}$ in the pancreas. AGAT has high $K_{\mathrm{m}}$ values for

(a)

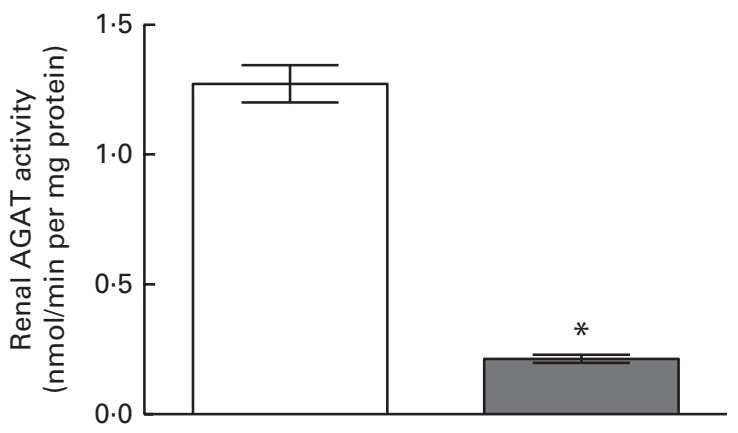

(b)

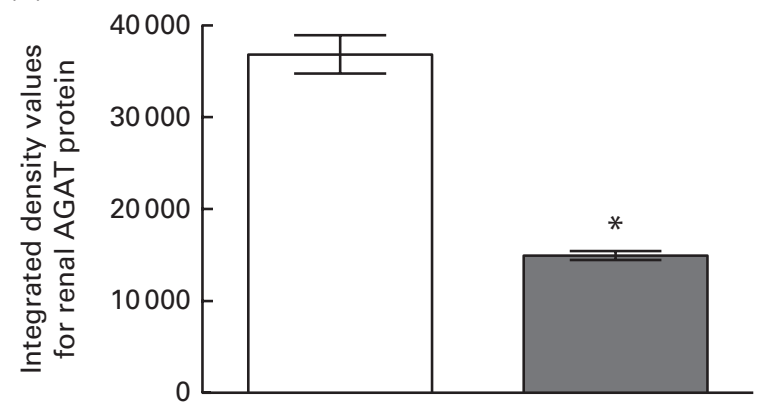

(c)

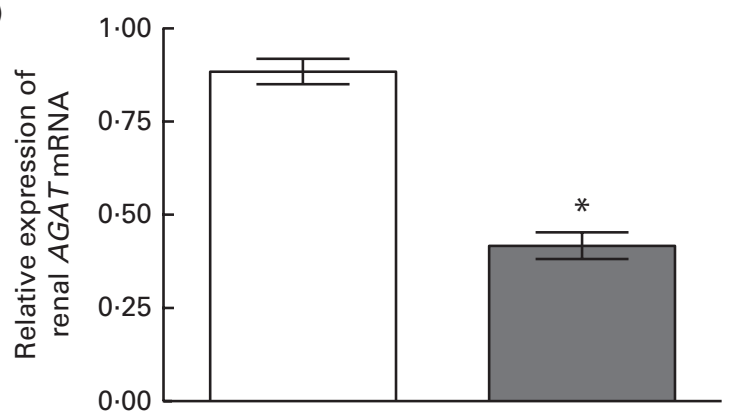

Fig. 2. Effect of dietary creatine on renal arginine:glycine amidinotransferase (AGAT). (a) Enzyme activity, (b) integrated density values from AGAT Western blotting and (c) relative expression of AGAT mRNA in the kidney. Creatine-free diet-fed group $(\square)$ and creatine-supplemented diet-fed group ( $\square)$. Data for mRNA target genes were normalised to 18S ribosomal RNA. Values are means ( $n 5)$, with their standard errors represented by vertical bars. * Mean values were significantly different between the dietary treatment groups $(P<0.05)$. 
Table 1. Metabolite concentrations in the pancreas of rats fed the creatine-free and creatine-supplemented diets

(Mean values with their standard errors, $n 5$ )

\begin{tabular}{lcccccc}
\hline & \multicolumn{2}{c}{$\begin{array}{c}\text { Creatine-free } \\
\text { diet-fed group }\end{array}$} & & \multicolumn{2}{c}{$\begin{array}{l}0.4 \% \text { Creatine } \\
\text { diet-fed group }\end{array}$} \\
\cline { 2 - 3 } Metabolites & Mean & SE & & Mean & SE \\
\hline GAA ( $\mu \mathrm{mol} / \mathrm{g}$ tissue) & 0.05 & 0.02 & & $0.22^{*}$ & 0.03 \\
Creatine $(\mu \mathrm{mol} / \mathrm{g}$ tissue) & 0.16 & 0.02 & & $0.44^{\star}$ & 0.05 \\
Phosphocreatine $(\mu \mathrm{mol} / \mathrm{g}$ tissue) & 0.20 & 0.03 & & $0.37^{*}$ & 0.05 \\
ATP ( $\mu \mathrm{mol} / \mathrm{g}$ tissue) & 0.98 & 0.15 & & 1.07 & 0.14 \\
SAM (nmol/g tissue) & 26.57 & 1.27 & & $17.40^{*}$ & 1.24 \\
SAH (nmol/g tissue) & 1.06 & 0.17 & & 0.84 & 0.02 \\
SAM/SAH & 27.2 & 3.4 & & 20.7 & 1.7 \\
\hline
\end{tabular}

GAA, guanidinoacetate; SAM, S-adenosylmethionine; SAH, S-adenosylhomocysteine.

* Mean values were significantly different between the dietary treatment groups $(P<0.05)$.

arginine (approximately $1-3 \mathrm{~mm}$ ) and glycine (approximately $2-3 \mathrm{~mm})^{(2)}$. This was consistent with the increase in GAA production when the concentrations of these amino acids were increased from 0.2 to $2 \mathrm{~mm}$. The sensitivity to arginine and glycine levels suggests that the transport of these substrates into pancreatic acini is not limiting for the synthesis of GAA in the pancreas and hence that plasma substrate concentrations influence GAA synthesis. However, creatine production in the pancreatic acini did not increase at higher substrate concentrations. The low activity of GAMT relative to the activity of AGAT may account for this observation. Thus, from the rates of GAA and creatine production and the enzyme activities measured in the pancreatic acini, we concluded that the capacity for GAA synthesis in the pancreas is much higher than that for creatine synthesis.

To gain a better insight into the potential impact that the pancreas might have on total body creatine synthesis in rats, we made some calculations of pancreatic creatine and GAA production. We calculated the rate of creatine synthesis in the presence of $0.2 \mathrm{~mm}$-arginine, $0.2 \mathrm{~mm}$-glycine and $0.5 \mathrm{~mm}$ methionine of $4.4 \mu \mathrm{mol}$ of creatine/d per $250 \mathrm{~g}$ rat tissue. This compares with the measured loss of creatinine of $55 \mu \mathrm{mol} / \mathrm{d}$ per $250 \mathrm{~g}$ rat tissue, which is equivalent to the daily renal GAA production ${ }^{(5)}$. Thus, the pancreas could produce as much as $8 \%$ of the creatine that is lost per $\mathrm{d}$. A similar calculation of GAA production yielded a rate of pancreatic GAA production of $8.3 \mu \mathrm{mol}$ of $\mathrm{GAA} / \mathrm{d}$ per $250 \mathrm{~g}$ rat $(15 \%$ renal GAA production). From the rates of GAA and creatine production and the enzyme activities measured in the pancreatic acini, we concluded that the capacity for GAA synthesis in the pancreas is much higher than that for creatine synthesis. Given that pancreatic venous blood drains into the hepatic portal vein and flows through the liver, it is possible that the pancreas releases GAA into the plasma to be used for creatine synthesis in the liver.

Phosphocreatine has been shown to be present in isolated perfused rat pancreas ${ }^{(16)}$ and to be dynamic, changing during acetylcholine-induced secretion of zymogens. ATP is known to be required for the secretion of zymogens by the exocrine pancreas ${ }^{(17)}$; ATP levels are thought to be maintained by creatine kinase phosphorylation of ADP from phosphocreatine $^{(16)}$.

Although the cells of the endocrine pancreas only represent a small fraction of the total cells, phosphocreatine is also important during secretion by these cells. Substantial creatine kinase activity has been found in islets isolated from mouse pancreas $^{(18)}$, and phosphocreatine has been shown to increase the response of the $K_{\mathrm{ATP}}$ channels in rat pancreatic islets ${ }^{(19)}$. $\mathrm{K}_{\mathrm{ATP}}$ channels are integral to the mechanism of the release of insulin from the $\beta$-cells of the pancreas. A recent study carried out by Rocić et al. ${ }^{(20)}$, which supports the role of the creatine kinase system in $\beta$-cells, has shown that the provision of creatine in the presence of various concentrations of glucose significantly increases ATP levels. In addition, Rocić et al. ${ }^{(20)}$ have shown that insulin secretion is increased by the provision of creatine, independent of the presence of added glucose, which suggests that changes in pancreatic creatine levels alone may impact insulin secretion by the $\beta$-cells. Marco et $a{ }^{(21)}$ have shown that creatine, GAA and arginine (at quite high concentrations) can significantly increase the secretion of glucagon and insulin in isolated pancreatic mouse islets. The mechanism through which guanidino compounds affect the release of hormones from pancreatic islets remains to be elucidated. However, there is good evidence from studies using inside-out patch clamps of mouse pancreatic $\beta$-cells that the addition of phosphocreatine prevents the opening of $\mathrm{K}_{\mathrm{ATP}}$ channels similar to the effect of added ATP, suggesting that phosphocreatine is involved in the regulation of insulin secretion through the modulation of ATP and ADP levels ${ }^{(22)}$.

Dietary creatine supplementation increased creatine and phosphocreatine content in whole pancreas. Thus, the pancreatic cells must be capable of transporting creatine. We predict that pancreatic islet cells would have SLC6A8, the well-known $\mathrm{Na}^{+}$-dependent creatine transporter. Pancreatic acini should have a creatine efflux transporter other than SLC6A8, since the $\mathrm{Na}$ gradient is in the wrong direction. A similar non-SLC6A8 transporter must be present in hepatic cells ${ }^{(23)}$. It is possible that high creatine concentrations in the plasma could enter the pancreas by reversal of this postulated transporter. The resultant increase in phosphocreatine concentrations presumably reflects the action of the reversible creatine kinase. It is not known whether such an increase affects exocrine and/or endocrine secretion.

The concentrations of GAA were increased in the pancreas of the creatine-supplemented diet-fed rats. This observation would appear to be at odds with the decreased AGAT activity

Table 2. Activities of arginine:glycine amidinotransferase (AGAT) and guanidinoacetate $N$-methyltransferase (GAMT) in the isolated pancreatic acini

(Mean values with their standard errors, $n 5$ )

\begin{tabular}{llr}
\hline & \multicolumn{2}{c}{$\begin{array}{c}\text { Activity } \\
\text { (nmol/min per mg protein) }\end{array}$} \\
\cline { 2 - 3 } Enzymes & Mean & SE \\
\hline AGAT & 3.41 & 0.61 \\
GAMT & 0.08 & 0.02 \\
\hline
\end{tabular}



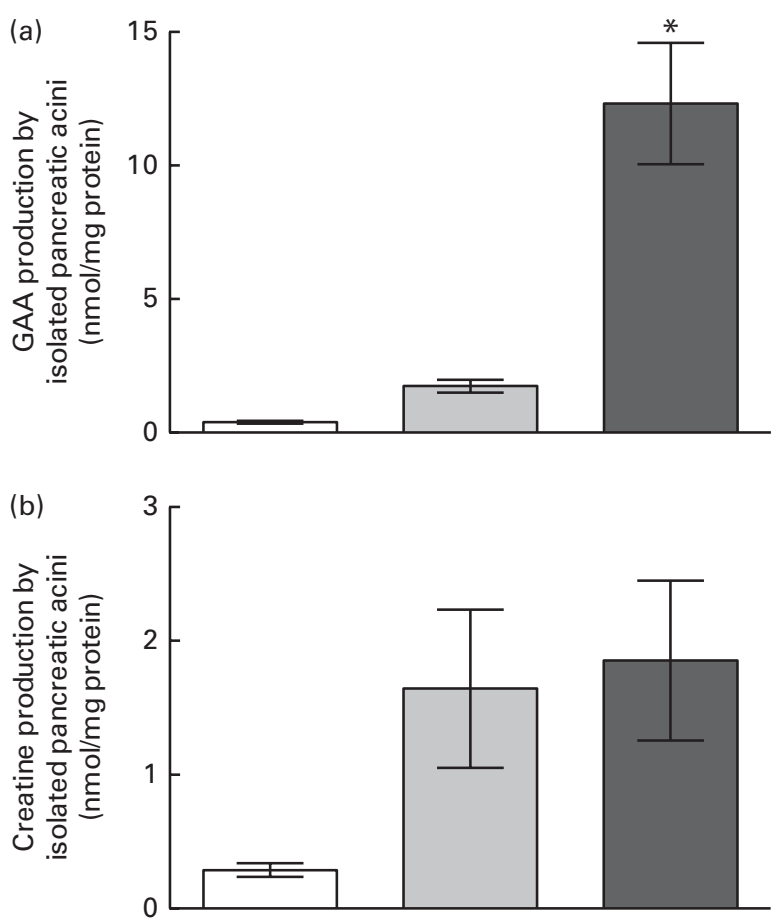

Fig. 3. Guanidinoacetate (GAA) and creatine production by acini isolated from the rat pancreas. (a) GAA production and (b) creatine production at time zero ( $\square$ ), after $40 \mathrm{~min}$ of incubation with $0.2 \mathrm{~mm}$-glycine and $0.2 \mathrm{~mm}$-arginine $(\square)$, and after $40 \mathrm{~min}$ of incubation with $2 \mathrm{~mm}$-glycine and $2 \mathrm{~mm}$-arginine ( $\square$ ). Values are means $(n 5)$, with their standard errors represented by vertical bars. *Mean values was significantly different between the $40 \mathrm{~min}$ incubations $(P<0.05)$.

observed in these rats, but an increase in the concentrations of GAA was also observed in the kidney (control group: 0.089 (sE 0.009); creatine-treated group: 0.111 (sE 0.012) $\mu \mathrm{mol} / \mathrm{g}, n 6$, $P<0 \cdot 01)$. Tissues that produce GAA would need a transporter to move it from the cells into the plasma. No transporter has been recognised yet, but it is possible that high creatine concentrations in the plasma may inhibit the movement of GAA out of the cells so that it accumulates, even at the lower AGAT activity observed in the pancreas and kidney. If so, this is additional evidence that pancreatic acini release GAA into the plasma.

We observed a high ratio of SAM:SAH in the pancreas, indicating that there is a high methylation potential in this organ. The pancreatic SAM:SAH ratio was 6-fold higher than that reported by us for the liver ${ }^{(24)}$. There is also evidence that the pancreas has a very active methionine cycle. Recently, Wilson et al. ${ }^{(25)}$ have shown, in a study using metabolic tracers, that among a comprehensive list of organs, the pancreas exhibits the highest production of homocysteine from methionine (per gram of tissue). Creatine supplementation appeared to have an effect on pancreatic methylation potential as the concentrations of SAM were significantly lower in the pancreas of the creatine-supplemented diet-fed rats. Since the activities of the methyltransferases would be decreased in the presence of lower SAM concentrations ${ }^{(26)}$, these data suggest that dietary creatine supplementation may have an impact on methylation in the pancreas.

The effect of dietary creatine on AGAT expression and activity in the pancreas appears to be different from that observed in the kidney. We found that dietary creatine reduces AGAT activity in the pancreas by about $34 \%$. In addition, we found that dietary creatine supplementation did not have an effect on AGAT mRNA and protein expression in the pancreas. This is quite different from what we observed in the kidney. Dietary creatine supplementation significantly decreased renal AGAT activity and protein and mRNA expression. This confirms the finding of the study carried out by McGuire et $a l .{ }^{(27)}$, who have shown that both renal AGAT activity and mRNA expression are significantly reduced by 74 and $63 \%$, respectively, by dietary creatine supplementation. Our data indicate that the pre-translational mechanism of regulation that responds to dietary creatine in the kidney may not occur in the pancreas.

In summary, we showed that pancreatic acini have activities of both AGAT and GAMT enzymes and are capable of producing GAA and creatine de novo. The capacity for GAA synthesis at elevated substrate concentrations is greater than that for creatine synthesis. We predict that some GAA may be secreted into the portal vein by the pancreatic acini. In addition, we showed the different effects of dietary creatine supplementation on AGAT activity and expression in the pancreas and kidney, indicating that the mechanisms of the regulation of AGAT activity in the pancreas may be differ from those in the pancreas.

\section{Acknowledgements}

The present study was funded by grants from the Canadian Institutes for Health Research (to J. T. B. and M. E. B.). R. P. d. S. was supported by a fellowship from the School of Graduate Studies at Memorial University of Newfoundland. The Canadian Institutes for Health Research had no role in the design and analysis of the study or in the writing of this article.

The authors' contributions were as follows: R. P. d. S., J. T. B. and M. E. B. designed the research; R. P. d. S. and K. C. conducted the research; R. P. d. S. analysed the data; R. P. d. S. and M. E. B. wrote the paper and had primary responsibility for the final content. All authors read and approved the final manuscript.

The authors have no conflicts of interest to disclose.

\section{References}

1. Wyss M \& Wallimann $\mathrm{T}$ (1992) Metabolite channelling in aerobic energy metabolism. J Theor Biol 158, 129-132.

2. Wyss M \& Kaddurah-Daouk R (2000) Creatine and creatinine metabolism. Physiol Rev 80, 1107-1213.

3. Komoto J, Yamada T, Takata Y, et al. (2004) Catalytic mechanism of guanidinoacetate methyltransferase: crystal structures of guanidinoacetate methyltransferse ternary complexes. Biochemistry 43, 14385-14394.

4. Van Pilsum JF, Stephens GC \& Taylor D (1972) Distribution of creatine, guanidinoacetate and enzymes for their 
biosynthesis in the animal kingdom. Implications for phylogeny. Biochem J 126, 325-345.

5. Edison EE, Brosnan ME, Meyer C, et al. (2007) Creatine synthesis: production of guanidinoacetate by the rat and human kidney in vivo. Am J Physiol Renal Physiol 293, F1799-F1804.

6. da Silva RP, Nissim I, Brosnan ME, et al. (2009) Creatine synthesis: hepatic metabolism of guanidinoacetate and creatine in the rat in vitro and in vivo. Am J Physiol Endocrinol Metab 296, E256-E261.

7. Braissant O \& Henry H (2008) AGAT, GAMT and SLC6A8 distribution in the central nervous system, in relation to creatine deficiency syndromes: a review. J Inherit Metab Dis 31, 230-239.

8. Sorenson RL, Stout LE, Brelje TC, et al. (1995) Evidence for the role of pancreatic acinar cells in the production of ornithine and guanidinoacetic acid by L-arginine:glycine amidinotransferase. Pancreas 10, 389-394.

9. Kempen HJ, de Pont JJ \& Bonting SL (1977) Rat pancreas adenylate cyclase $\mathrm{V}$. Its presence in isolated rat pancreatic acinar cells. Biochim Biophys Acta 496, 521-531.

10. Guthmiller P, Van Pilsum JF, Boen JR, et al. (1994) Cloning and sequencing of rat kidney L-arginine:glycine amidinotransferase. Studies on the mechanism of regulation by growth hormone and creatine. J Biol Chem 269, 17556-17560.

11. Blinman TA, Gukovsky I, Mouria M, et al. (2000) Activation of pancreatic acinar cells on isolation from tissue: cytokine upregulation via p38 MAP kinase. Am J Physiol Cell Physiol 279, C1993-C2003.

12. Van Pilsum JF, Taylor D, Zakis B, et al. (1970) Simplified assay for transamidinase activities of rat kidney homogenates. Anal Biochem 35, 277-286.

13. Buchberger W \& Ferdig M (2004) Improved high-performance liquid chromatographic determination of guanidino compounds by precolumn derivatization with ninhydrin and fluorescence detection. J Sep Sci 27, 1309-1312.

14. Lowry OH \& Passonneau JV (1972) A Flexible System of Enzymatic Analysis. New York, NY: Academic Press pp. $151-156$.

15. Jacobs RL, Stead LM, Devlin C, et al. (2005) Physiological regulation of phospholipid methylation alters plasma homocysteine in mice. J Biol Chem 280, 28299-28305.
16. Matsumoto T, Kanno T, Seo Y, et al. (1988) Phosphorus nuclear magnetic resonance in isolated perfused rat pancreas. Am J Physiol 254, G575-G579 (Gastrointest Liver Physiol 17).

17. Petersen $\mathrm{OH}$ (2012) Specific mitochondrial functions in separate sub-cellular domains of pancreatic acinar cells. Pflugers Arch 464, 77-87.

18. Panten U, Zünkler BJ, Scheit S, et al. (1986) Regulation of energy metabolism in pancreatic islets by glucose and tolbutamide. Diabetologia 29, 648-654.

19. Krippeit-Drews P, Bäcker M, Düfer M, et al. (2003) Phosphocreatine as a determinant of $\mathrm{K}_{\mathrm{ATP}}$ channel activity in pancreatic $\beta$-cells. Pflugers Arch 445, 556-562.

20. Rocić B, Lovrencić MV, Poje M, et al. (2007) Effect of creatine on the pancreatic beta-cell. Exp Clin Endocrinol Diabetes 115, 29-32.

21. Marco J, Calle C, Hedo JA, et al. (1976) Glucagon-releasing activity of guanidine compounds in mouse pancreatic islets. FEBS Lett 64, 52-54.

22. Schulze DU, Düfer M, Wieringa B, et al. (2007) An adenylate kinase is involved in $\mathrm{K}_{\mathrm{ATP}}$ channel regulation of mouse pancreatic beta cells. Diabetologia 50, 2126-2134.

23. Speer O, Neukomm LJ, Murphy RM, et al. (2004) Creatine transporters: a reappraisal. Mol Cell Biochem 256/257, 407-424.

24. Jacobs RL, Stead LM, Brosnan ME, et al. (2001) Hyperglucagonemia in rats results in decreased plasma homocysteine and increased flux through the transsulfuration pathway in liver. J Biol Chem 276, 43740-43747.

25. Wilson FA, van den Borne JJ, Calder AG, et al. (2009) Tissue methionine cycle activity and homocysteine metabolism in female rats: impact of dietary methionine and folate plus choline. Am J Physiol Endocrinol Metab 296, E702-E713.

26. Clarke S \& Banfield K (2001) S-Adenosylmethionine-dependent methyltransferases. In Homocysteine in Health and Disease, pp. 63-78 [R Carmel and DW Jacobsen, editors]. Cambridge: Cambridge University Press.

27. McGuire DM, Gross MD, Van Pilsum JF, et al. (1984) Repression of rat kidney L-arginine:glycine amidinotransferase synthesis by creatine at a pretranslational level. J Biol Chem 259, 12034-12038. 